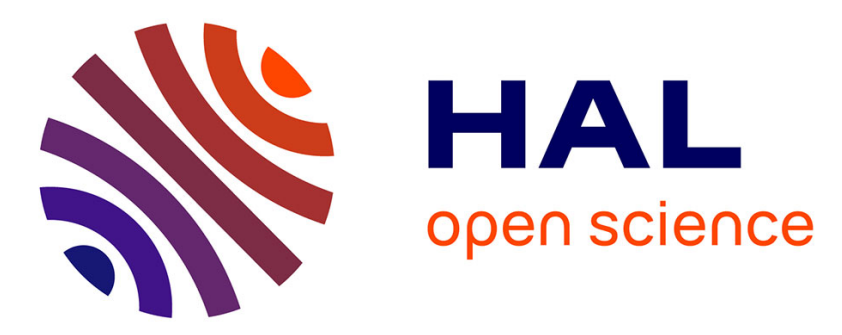

\title{
Risk and Preference Reversals in Intertemporal Choice
} Anke Gerbe, Kirsten I.M. Rohde

\section{To cite this version:}

Anke Gerbe, Kirsten I.M. Rohde. Risk and Preference Reversals in Intertemporal Choice. Journal of Economic Behavior and Organization, 2010, 76 (3), pp.654. 10.1016/j.jebo.2010.09.005 . hal00911832

\section{HAL Id: hal-00911832 \\ https://hal.science/hal-00911832}

Submitted on 30 Nov 2013

HAL is a multi-disciplinary open access archive for the deposit and dissemination of scientific research documents, whether they are published or not. The documents may come from teaching and research institutions in France or abroad, or from public or private research centers.
L'archive ouverte pluridisciplinaire HAL, est destinée au dépôt et à la diffusion de documents scientifiques de niveau recherche, publiés ou non, émanant des établissements d'enseignement et de recherche français ou étrangers, des laboratoires publics ou privés. 


\section{Accepted Manuscript}

Title: Risk and Preference Reversals in Intertemporal Choice

Authors: Anke Gerbe, Kirsten I.M. Rohde

PII: $\quad$ S0167-2681(10)00182-4

DOI: $\quad$ doi:10.1016/j.jebo.2010.09.005

Reference: $\quad$ JEBO 2609

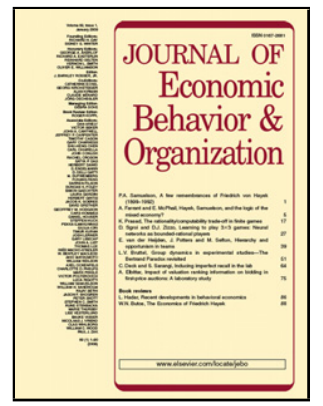

To appear in: Journal of Economic Behavior \& Organization

Received date: $\quad 16-9-2008$

Revised date: $\quad 3-9-2010$

Accepted date: $\quad$ 5-9-2010

Please cite this article as: Gerbe, A., Rohde, K.I.M., Risk and Preference Reversals in Intertemporal Choice, Journal of Economic Behavior and Organization (2010), doi:10.1016/j.jebo.2010.09.005

This is a PDF file of an unedited manuscript that has been accepted for publication. As a service to our customers we are providing this early version of the manuscript. The manuscript will undergo copyediting, typesetting, and review of the resulting proof before it is published in its final form. Please note that during the production process errors may be discovered which could affect the content, and all legal disclaimers that apply to the journal pertain. 


\title{
Risk and Preference Reversals in Intertemporal Choice*
}

\author{
Anke Gerber ${ }^{\dagger} \quad$ Kirsten I.M. Rohde ${ }^{\ddagger}$
}

August 31, 2010

\footnotetext{
${ }^{*}$ The authors would like to thank Peter P. Wakker for helpful comments. Part of this research has been carried out within the project on "Behavioural and evolutionary finance" of the National Centre of Competence in Research "Financial Valuation and Risk Management" (NCCR FINRISK). The NCCR FINRISK is a research instrument of the Swiss National Science Foundation. Kirsten Rohde's research was made possible through a VENI grant from the Netherlands Organization for Scientific Research (NWO).

${ }^{\dagger}$ Department of Economics, Hamburg University, Von-Melle-Park 5, 20146 Hamburg, Germany, e-mail: anke.gerber@wiso.uni-hamburg.de

${ }^{\ddagger}$ Department of Economics, H13-27, Erasmus University, P.O. Box 1738, 3000 DR Rotterdam, the Netherlands, e-mail: rohde@ese.eur.nl
} 


\begin{abstract}
This paper argues that observations of non-stationary choice behavior need not necessarily imply specific properties of the individual's discount function. As we show, the observed preference reversals in intertemporal choice are consistent with constant discounting and can alternatively be explained by decreasing absolute risk aversion together with the individual's risk perception. This risk may concern the size of the actual outcome or the endowment consumption stream to which the outcome is added. Both types of uncertainty naturally appear in the context of intertemporal choice. We show how relative degrees of changes in risk over time can determine choices.
\end{abstract}

Keywords: Hyperbolic Discounting, Decreasing Impatience, Increasing impatience, Risk

JEL classification: D91, D81 


\section{Introduction}

Individuals generally value immediate payoffs higher than later payoffs, i.e. they discount future payoffs. There are many reasons for discounting future outcomes (Frederick, Loewenstein, and O'Donoghue, 2002). One of them is that the future is risky and that there is a positive probability that we will no longer be alive in the future. In this paper we will not focus on the fact that risk causes impatience as such. We will rather study how the interaction of risk and impatience influences choice behavior over time. More specifically, we will analyze the extent to which we can draw conclusions about the curvature of an individual's discount function merely from observing choice behavior.

A widely used model in intertemporal choice that captures an individual's impatience is discounted utility. For a long time Samuelson's (1937) constant, that is exponential, discounting has been the most popular model for decision making in economics. Under constant discounting preferences satisfy stationarity, i.e. the preference between two streams of outcomes does not change if the delivery of every outcome in both streams is postponed by a common delay. Under some additional assumptions stationarity implies time-consistent behavior.

Strotz (1956) was the first to analyze a formal economic model with time-inconsistent preferences. Since then many psychological and economic studies have found evidence against stationary behavior (Benzion, Rapoport, and Yagil, 1989; Bleichrodt and Johannesson, 2001; Cairns and van der Pol, 2000; Green, Fristoe, and Myerson, 1994; Kirby and Marakovic, 1995; Mazur, 1987, 2001; Read and Read, 2004; Rodriguez and Logue, 1988; and Thaler, 1981). Most studies found decreasing impatience, as in Thaler's (1981) example of a person who prefers one apple today over two apples tomorrow, but at the same time prefers two apples in 51 days over one apple in 50 days. Loewenstein and Prelec (1992) called this the "common difference effect." As a consequence of the empirical evidence in favor of decreasing impatience, quasi-hyperbolic (Phelps and Pollak, 1968) and generalized hyperbolic discounting (Loewenstein and Prelec, 1992) were introduced. These discount functions satisfy decreasing impatience. Hyperbolic discounting models are be- 
coming increasingly popular in applications (Angeletos et al., 2001; Barro 1999; Harris and Laibson, 2001; Herings and Rohde, 2006; Krusell and Smith, 2003; Laibson, 1997; Luttmer and Mariotti, 2003, 2006; O'Donoghue and Rabin, 1999a, 1999b; Rohde, 2008; and Thaler and Benartzi, 2004).

This paper shows that non-stationarity may be less of an anomaly than has often been thought and instead can be fully compatible with Samuelson's (1937) constant discounting. We will show that non-stationary behavior occurs when subjects perceive their endowments or outcomes as risky, even when they satisfy constant discounting. Both types of risk naturally appear in the context of intertemporal choice. When choosing between two different outcomes the decision maker (DM) determines his preference between the consumption streams that result if the outcomes are added to his endowment consumption. Since the latter involves future consumption, it seems natural to assume that the DM considers the endowment to be subject to risk. ${ }^{1}$ At the same time any outcome that is to be received in the future may itself be considered risky. Whoever has promised to deliver the outcome may fail on the obligation. Whether the DM takes into account outcome risk depends, among other things, on the reputation of the individual or institution who has promised the outcome and on the precautions that have been taken in order to guarantee its delivery. Keren and Roelofsma (1995) and Benzion, Rapoport, and Yagil (1989) discussed before that risk may be underlying some of the findings of non-constant discounting. The second half of this paper formalizes their ideas.

In general both endowments and outcomes will be risky. However, in order to study the influence of each type of risk on the DM's choice behavior we analyze both types of risk in isolation. We show that for a DM who satisfies constant discounting observed behavior may suggest increasing impatience, i.e. we observe an i-reversal, whenever the increase in endowment risk in the near future is relatively large compared to the increase in endowment risk in the far future, or whenever the increase in outcome risk in the near future is relatively small compared to the increase in outcome risk in the far future.

\footnotetext{
${ }^{1}$ The role of this background risk for decisions making under risk has also been studied by Gollier and Pratt (1996) and Eeckhoudt et al. (1996).
} 


\begin{tabular}{l||c|c||}
\multicolumn{2}{c}{ Increase in risk in the near future } \\
\multicolumn{2}{c}{ relative to } \\
& large & small \\
\hline \hline endowment risk & i-reversal & d-reversal \\
\hline outcome risk & d-reversal & i-reversal \\
\hline \hline
\end{tabular}

Table 1: Predictions for a DM with constant discounting.

Conversely, when endowment risk increases relatively strongly in the far compared to the near future, or when outcome risk increases relatively strongly in the near compared to the far future, the DM's behavior may suggest decreasing impatience, i.e. we observe a d-reversal. Thus, endowment risk and outcome risk are countervailing forces. Table 1 summarizes these results. The main reason for these findings is that under decreasing absolute risk aversion, whenever endowments become riskier, it becomes more valuable to receive an outcome on top of these endowments, while if an outcome becomes riskier, it becomes less valuable to receive that outcome on top of endowments. Hence, a DM who today is willing to wait for a larger (riskless) outcome will be less willing to wait in the future, if the increase in endowment risk is smaller in the future relative to today. By contrast, a DM who today is not willing to wait for a larger risky outcome will be more willing to wait in the future, if the increase in outcome risk is smaller in the future relative to today.

This paper is related to Noor (2009), who shows that under constant discounting all anomalies in intertemporal choice, except for intransitivity, can be explained by changes in future endowments. The papers are complementary in the sense that Noor rationalizes observed behavior by perceived deterministic increases in future endowments while we rationalize behavior by perceived risk in future endowments or outcomes. Moreover, we show that all kinds of preference reversals can be obtained for a discount function satisfying increasing, constant or decreasing impatience even if we take the decision maker's utility 
function as given and only vary the perceived risk.

Several recent studies also analyze the effect of risk or uncertainty on intertemporal choice and its implications on the anomalies often found. Fernández-Villaverde and Mukherji (2006) consider a framework with uncertainty concerning the utility that a particular outcome will yield. Their framework does allow for the endowment and outcome risks that we consider. They focus on behavior that suggests decreasing impatience and assume that uncertainty does not increase in the future. We aim to give a thorough discussion on how two sources of risk, namely endowment and outcome risk, can have countervailing influences on behavior and do not rule out continuously increasing uncertainty.

Dasgupta and Maskin (2005) assume that the timing of outcomes is risky. Bommier (2006) and Halevy (2008) consider uncertainty about lifetime. Halevy (2008) needs the assumption that decision-makers weight probabilities non-linearly, which we do not need. Boyarchenko and Levendorskii (2006) assume that outcomes are risky. The decision makers in their study pay, or receive, a particular amount at a particular date $t$ in order to receive, or pay, an outcome $T$ dates later. The decision maker can choose date $t$. Thus, the receipt of the outcome $T$ dates later in return for a payment today is seen as an option which can be exercised at any date $t$ either with or without a limit. The authors use option pricing theory to show that this setting produces the common intertemporal choice anomalies, even though the underlying discounting is constant. The main differences between their approach and ours are that they use the theory of real options, which we do not, and that they do not make the distinction between outcome and endowment risk, which we do.

Finally, apart from many studies that find decreasing impatience, there are also studies that do not find such evidence (Read et al., 2005; Rubinstein, 2003). Some even find increasing impatience (Attema et al., 2010; Chesson and Viscusi, 2003; Frederick, 1999; Gigliotti and Sopher, 2003; Onay and Oncüler, 2007; Read, Airoldi and Loewe, 2005; Sayman and Oncüler, 2009). Our results provide a simple and intuitive explanation for this observed increasing impatience. Also, we show how decreasing, constant, and increasing impatience can all be observed in one natural and simple model. Thus, the studies finding increasing impatience do not necessarily contradict the studies that found decreasing 
impatience.

This paper is organized as follows. Section 2 introduces the general setting that we consider and the assumptions made. The next two sections consider the case of risky endowments (Section 3) and the case of risky outcomes (Section 4). Section 5 concludes. All proofs are in the Appendix.

\section{The setting}

This section introduces basic notation and concepts. The set of nonnegative real numbers is denoted by $\mathbb{R}_{+}$. The set $\mathcal{R}$ is the set of all random variables with realizations in $\mathbb{R}$ and with finite expectation. $\mathcal{R}^{k}$ contains all $k$-tuples of independently distributed random variables. For two random variables $x, y \in \mathcal{R}, x={ }_{d} y$ means that $x$ has the same distribution as $y$.

We consider a decision-maker (DM) who has a lifetime or planning horizon of $T$ periods. Date $t=0$ corresponds to 'today' and date $T$ is the final period. The DM has a complete and transitive preference relation $\succcurlyeq$ on $\mathcal{R}^{T+1}$. He has an endowment $\omega=\left(\omega_{0}, \ldots, \omega_{T}\right) \in$ $\mathcal{R}^{T+1}$. A typical example for a DM's endowment is his current and future income. A different example arises if the DM only evaluates deviations from some reference income as in Prospect Theory (Kahneman and Tversky, 1979). In this case the DM's endowment in any period is given by the deviation of his actual income from the reference income.

We assume that date-0-endowment is riskless, i.e. $\operatorname{Var}\left(\omega_{0}\right)=0$, whereas date- $t$-endowment $\omega_{t}$ in general will be a random variable. ${ }^{2}$ The endowment $\omega_{t}$ is riskless, whenever $\operatorname{Var}\left(\omega_{t}\right)=0$ and it is risky otherwise. If $\omega_{t}$ is riskless we identify $\omega_{t}$ with $E\left(\omega_{t}\right) \in \mathbb{R}$. Endowment risk is i.i.d. if endowments for all future dates $t>0$ are independently and identically distributed. Endowment $\omega_{\bar{t}}$ is a mean-preserving spread of $\omega_{t}$ if $\omega_{\bar{t}}={ }_{d} \omega_{t}+\varepsilon$ and $\omega_{\bar{t}} \neq_{d} \omega_{t}$, with $\varepsilon \in \mathcal{R}$ and $E\left(\omega_{\bar{t}} \mid \omega_{t}=w_{t}\right)=w_{t}$ for all realizations $w_{t}$ of $\omega_{t}$. We say that endowment risk is increasing if $\omega_{\bar{t}}$ is a mean-preserving spread of $\omega_{t}$ for every $0 \leq t<\bar{t} \leq T$. It seems reasonable to assume that endowment risk is increasing over time. For example, if wealth is invested on financial markets and asset prices follow a random walk, then the

\footnotetext{
${ }^{2}$ We use the notation $\operatorname{Var}$ to denote the variance and $E$ to denote the expectation of a random variable.
} 
endowment risk is clearly increasing over time. Also, if the endowment is given by the DM's wage income, then it seems plausible to assume that income risk is increasing over time since, among others, the employment status and wage income depends upon the overall state of the economy which itself can be assumed to be subject to increasing risk. ${ }^{3}$

Throughout this paper a DM will have a choice between receiving one outcome $x \in \mathcal{R}$ at a particular date or another outcome $y \in \mathcal{R}$ at another date. We use the notation $(t: x)$ to indicate that on top of the endowment, the DM receives outcome $x \in \mathcal{R}$ at time $t \in \mathcal{T}=\{0, \ldots, T\}$, where $x$ can be riskless or risky and is always independently distributed from endowments. We call $(t: x)$ a dated outcome. We assume that the outcome $x$ is consumed at the date when it is received. Thus, a DM who receives $(t: x)$ consumes the consumption stream $\xi^{(t: x)}=\left(\xi_{0}^{(t: x)}, \xi_{1}^{(t: x)}, \ldots, \xi_{T}^{(t: x)}\right) \in \mathcal{R}^{T+1}$ with $\xi_{t}^{(t: x)}=\omega_{t}+x$ and $\xi_{t^{\prime}}^{(t: x)}=\omega_{t^{\prime}}$ for all $t^{\prime} \neq t$. Let $\mathcal{X}$ be the set of all dated outcomes $(t: x)$ such that $t \in \mathcal{T}$, $x \in \mathcal{R}$, and $x$ and $\omega_{t}$ are independently distributed. The DM's preference relation $\succcurlyeq$ on consumption streams defines an induced preference relation $\succcurlyeq^{*}$ on $\mathcal{X}$ as follows. Let $(t: x),\left(t^{\prime}: y\right) \in \mathcal{X}$. Then

$$
(t: x) \succcurlyeq^{*}\left(t^{\prime}: y\right) \text { if and only if } \xi^{(t: x)} \succcurlyeq \xi^{\left(t^{\prime}: y\right)}
$$

Thus, $(t: x) \succcurlyeq^{*}\left(t^{\prime}: y\right)$ means that the DM weakly prefers the consumption stream where on top of his endowment he receives $x$ at date $t$, over the consumption stream where on top of his endowment he receives $y$ at date $t^{\prime}$. From completeness and transitivity of $\succcurlyeq$ it follows that that $\succcurlyeq^{*}$ is complete and transitive. This paper addresses the question to what extent we can draw conclusions about preferences $\succcurlyeq$ from observing induced preferences $\succcurlyeq^{*}$.

\footnotetext{
${ }^{3}$ One may argue that the expected endowment may not be constant over time but instead changes over the DM's life cycle. We restrict to a fixed expected endowment for two reasons. First, in many experiments on intertemporal choice the time horizon is rather short and hence there are good reasons to assume that the average endowment is constant. Second, we want to point out the influence of risk on intertemporal choice and to this end we rule out any other factors that may influence intertemporal decision making like increases or decreases in expected future income (cf. Noor, 2009).
} 
We assume throughout that $\succcurlyeq$ can be represented by a discounted expected utility function:

$$
\xi \succcurlyeq \xi^{\prime} \Longleftrightarrow \sum_{t=0}^{T} \delta(t) E U\left(\xi_{t}\right) \geq \sum_{t=0}^{T} \delta(t) E U\left(\xi_{t}^{\prime}\right),
$$

for $\xi, \xi^{\prime} \in \mathcal{R}^{T+1}$, where $\delta$ is a discount function and $E U$ stands for the expected utility associated with a von Neumann-Morgenstern utility function $U: \mathbb{R} \rightarrow \mathbb{R}$. We assume that the utility function $U$ is three times continuously differentiable, increasing $\left(U^{\prime}>0\right)$ and strictly concave $\left(U^{\prime \prime}<0\right)$. Moreover, we assume that $U$ satisfies strictly decreasing absolute risk aversion:

Assumption $\mathbf{I}-U^{\prime \prime}(x) / U^{\prime}(x)$ is strictly decreasing in $x$ for all $x \in \mathbb{R}$.

Observe that monotonicity together with decreasing absolute risk aversion implies that $U^{\prime \prime \prime}>0$. Let $x \in \mathbb{R}$ and $\varepsilon \in \mathcal{R}$ be such that $E U(x+\varepsilon)$ exists and is finite. Then by $\pi(x, \varepsilon)$ we denote the risk premium for the risk $\varepsilon$ at $x$, i.e. $\pi(x, \varepsilon)$ is defined by

$$
E U(x+\varepsilon)=U(x+E(\varepsilon)-\pi(x, \varepsilon)) .
$$

The utility function $U$ satisfies strictly decreasing absolute risk aversion if and only if $\pi(x, \varepsilon)$ is strictly decreasing in $x$ for all $\varepsilon \in \mathcal{R}$ with a nondegenerate distribution, i.e. with $\operatorname{Prob}(\varepsilon=E(\varepsilon))<1$ (Pratt, 1964).

The discount function $\delta$ is assumed to be strictly decreasing in $t(\delta(\bar{t})<\delta(t)$ for $\bar{t}>t)$, and to satisfy $\delta(t)>0$ for all $t \in \mathcal{T}$, and $\delta(0)=1$. The discount function satisfies decreasing (constant, increasing) impatience if outcomes that are received in the far future are discounted less (equally, more) than outcomes that are received in the near future. This is formalized in the following definition which is equivalent to Prelec's (2004) definition.

\section{Definition 2.1}

The discount function $\delta$ satisfies decreasing (constant, increasing) impatience if for all $t, \bar{t}$ with $t<\bar{t}$ and for all $\tau>0$

$$
\frac{\delta(t)}{\delta(t+\tau)}>(=,<) \frac{\delta(\bar{t})}{\delta(\bar{t}+\tau)}
$$


Constant impatience is equivalent to Samuelson's (1937) constant discounting: there is a constant $\phi<1$ such that $\delta(t)=\phi^{t}$ for every $t$.

Throughout the paper we assume that at every date the expected utility of the endowment exists and is finite.

Assumption II For all $t,\left|E U\left(\omega_{t}\right)\right|<\infty$.

Assumption II in particular holds for all endowments $\omega$ where $\omega_{t}$ has a bounded support for all $t$.

It is assumed throughout that the utility function $U$ is known and that the discount function $\delta$ is not known. Imagine, for instance, an experimenter who elicited the utility function from the DM through the observation of choices between outcomes that are received immediately, i.e. at date 0 . Now, by observing choices between dated outcomes, i.e. by observing induced preferences, he wants to elicit the DM's discount function under the assumption that the DM has a discounted expected utility function. Under discounted expected utility $(t: x) \succcurlyeq^{*}\left(t^{\prime}: y\right)$ if and only if

$$
\delta(t)\left[E U\left(\omega_{t}+x\right)-E U\left(\omega_{t}\right)\right] \geq \delta\left(t^{\prime}\right)\left[E U\left(\omega_{t^{\prime}}+y\right)-E U\left(\omega_{t^{\prime}}\right)\right]
$$

We say that the induced preference $(t: x) \succcurlyeq^{*}\left(t^{\prime}: y\right)$ can be supported by a discount function $\delta$ if (1) holds for that particular $\delta$.

\section{Choices under endowment risk}

This section will show that induced preferences that, at first sight, suggest decreasing or increasing impatience in fact do not rule out constant impatience. The results are driven by a change in endowment risk over time. In order to focus on the effect of endowment risk 
we only consider riskless outcomes in this section. As we will show, a choice pattern that suggests decreasing impatience can be observed for a discounted expected utility function with constant or even increasing impatience when the change in endowment risk in the near future is small compared to that change in the far future. Similarly, a choice pattern suggesting increasing impatience can be observed for a discounted expected utility function with constant or even decreasing impatience as long as the change in endowment risk in the near future is relatively large compared to the change in risk in the far future. Hence, since perceived endowment risk is unobservable, one has to be careful when drawing conclusions about discount functions from observed behavior in intertemporal choice. In experiments it may therefore be instructive to elicit subjects' perceived change in endowment risk over time.

The results in this paper are driven by second-order changes in perceived risk: changes in changes in perceived risk. Thus, we do not require large changes in the perception of risk. If perceived risk changes only slightly, then still the change in the change in risk can be such that it generates our results. Thus, our results hold even for experiments or choices that consider only short horizons and small amounts of money.

\section{D-REVERSALS}

We start by considering a d-reversal, which is the most commonly observed preference reversal.

\section{Definition 3.1 d-reversal}

Induced preferences $\succcurlyeq^{*}$ exhibit a d-reversal at the riskless outcomes $y>x>0$ and dates $\bar{t}>t \geq 0$ and $\tau>0$ if

$$
(t: x) \sim^{*}(t+\tau: y) \&(\bar{t}: x) \prec^{*}(\bar{t}+\tau: y) .^{4}
$$

\footnotetext{
${ }^{4}$ If a d-reversal exists, then by continuity and monotonicity we can also find outcomes $x^{\prime}$ and $y^{\prime}$ close to $x$ and $y$ such that $\left(t: x^{\prime}\right) \succ^{*}\left(t+\tau: y^{\prime}\right) \&\left(\bar{t}: x^{\prime}\right) \prec^{*}\left(\bar{t}+\tau: y^{\prime}\right)$.
} 
A d-reversal seems to suggest decreasing impatience: The DM is indifferent between receiving $x$ at date $t$ and waiting for the larger outcome $y$ to be received at date $t+\tau$, but once the receipt of both outcomes is delayed by the same amount of time, the DM prefers to wait for the better outcome. Indeed, without uncertainty, a d-reversal would imply decreasing impatience.

As we will show next, d-reversals in fact do not rule out constant or even increasing impatience when endowments are risky. In particular, a d-reversal does not necessarily contradict Samuelson's (1937) constant discounting. To give an intuition for this result observe that obtaining a positive payoff on top of a risky endowment has two effects. First, it increases wealth at the given date. Second, the DM can cope better with the risk involved in consumption at that date, because at a higher wealth level he is less risk averse due to strictly decreasing absolute risk aversion. Hence, upon receiving a positive and riskless payoff the DM suffers less from the endowment risk. The larger the increase in risk over time, the more valuable it is to delay the receipt of an outcome. Suppose that the increase in endowment risk is larger in the far than in the near future. Then, it is relatively more valuable to delay the receipt of an outcome in the far than in the near future. ${ }^{5}$

Hence, if the DM is indifferent between receiving outcome $x$ at date $t$ and receiving outcome $y$ at date $t+\tau$, then at date $\bar{t}>t$, when the increase in risk is larger, waiting for outcome $y$ becomes more valuable, because the risk to be compensated is larger. This explains a d-reversal. The next theorems will formalize this intuition.

Theorem 3.2 Let the DM satisfy a d-reversal, i.e.

$$
(t: x) \sim^{*}(t+\tau: y) \&(\bar{t}: x) \prec^{*}(\bar{t}+\tau: y)
$$

where $y>x>0$, and $\bar{t}>t \geq 0, \tau>0$. Then there exist endowments with increasing endowment risk, such that the reversal can be supported by a discount function satisfying constant impatience.

\footnotetext{
${ }^{5} \mathrm{By}$ far future we mean the further future. Thus, the far future may be 'tomorrow' if we take the near future being 'in two hours'.
} 
Remark 3.3 The d-reversal in Theorem 3.2 can even be supported by a discount function satisfying increasing impatience. In particular, it can be supported by the constant relative decreasing impatience (CRDI) discount function with $\delta(t)=\exp \left(-b t^{1+g}\right)$ for some $b, g>0$, that was introduced by Ebert and Prelec (2007) and Bleichrodt, Rohde, and Wakker (2009).

The next theorem provides conditions for d-reversals to be observed under constant impatience when endowment risks are given.

Theorem 3.4 Let $y>x>0, \bar{t}>t \geq 0$, and $\tau>0$. Let endowment risk be increasing and let the DM's discount function satisfy constant impatience. Then, for every $M$ there is an $N$ such that if

$$
\begin{gathered}
\left|\left(E U\left(\omega_{\bar{t}+\tau}+y\right)-E U\left(\omega_{\bar{t}+\tau}\right)\right)-\left(E U\left(\omega_{t+\tau}+y\right)-E U\left(\omega_{t+\tau}\right)\right)\right|>M \text { and } \\
\left|\left(E U\left(\omega_{\bar{t}}+x\right)-E U\left(\omega_{\bar{t}}\right)\right)-\left(E U\left(\omega_{t}+x\right)-E U\left(\omega_{t}\right)\right)\right|<N
\end{gathered}
$$

and if

$$
(t: x) \sim^{*}(t+\tau: y)
$$

then

$$
(\bar{t}: x) \prec^{*}(\bar{t}+\tau: y)
$$

The crucial assumption in Theorem 3.4 is that, from the point of view of the DM, the increase in endowment risk in the far future is relatively large (Eq. 2) compared to the increase in risk in the near future (Eq. 3).

Remark 3.5 If the DM's discount function is given by $\delta(t)=\exp \left(-b t^{1+g}\right)$ with $b, g>0$, then, under the conditions of Theorem 3.4, $(t: x) \sim^{*}(t+\tau: y)$ implies that $(\bar{t}: x) \prec^{*}$ $(\bar{t}+\tau: y)$ if $g$ is sufficiently small.

The next example illustrates the findings of Theorems 3.2 and 3.4. 
Example 3.6 As an example we will illustrate how the data of experiment 1 in Read and Roelofsma (2003) could be explained by changes in risk rather than decreasing impatience. The individuals in that experiment were on average indifferent between receiving Dfl. 100 (Dutch Guilders, 1 Guilder being approximately 60 cents or 40 pence) immediately or Dfl. 128 in 8 weeks or Dfl. 153 in 16 weeks (see Read and Roelofsma 2003, table 2, LL, interval 16 split in 2).

Consider an individual with CRRA utility function $U(x)=-x^{1-c}$ with $c>1$ the coefficient of relative risk aversion and $x$ his weekly consumption in Dutch Guilders. Throughout this example we will consider three possible values for $c: 1.5,2$, and 2.5. Assume that this week the individual expects to consume $w$. As the subjects were students, we let $w$ be 300 , 400, or 500 (all numbers denoted in Dfl.).

First assume that the individual does not perceive his expected consumption to be risky. Thus, in 8 weeks and in 16 weeks he expects to consume $w$ per week as well. We will show that the observed indifferences $(0$ weeks : 100) (8 weeks : 128) (16 weeks : 153) together imply decreasing impatience at these particular dates. The first indifference, (0 weeks : 100) (8 weeks : 128), implies an 8-weekly discount factor of

$$
\delta(8)=\frac{U(w+100)-U(w)}{U(w+128)-U(w)} .
$$

The second indifference, (8 weeks : 128) (16 weeks : 153), implies that the 16-weekly discount factor $\delta(16)$ satisfies

$$
\frac{\delta(16)}{\delta(8)}=\frac{U(w+128)-U(w)}{U(w+153)-U(w)}
$$

For $w \in\{300,400,500\}$, and for all possible values of $c \in\{1.5,2,2.5\}$ we have that $\delta(16)>$ $\delta(8)^{2}$, which is the case only under decreasing impatience.

Now assume that the individual perceives his future expected weekly consumption to be risky. In 8 weeks, he expects to consume either $w\left(1+d w_{8}\right)$ or $w\left(1-d w_{8}\right)$, both with $50 \%$ probability. In 16 weeks he expects to consume $w\left(1+d w_{8}\right)\left(1+d w_{16}\right), w\left(1+d w_{8}\right)\left(1-d w_{16}\right)$, $w\left(1-d w_{8}\right)\left(1+d w_{16}\right)$, or $w\left(1-d w_{8}\right)\left(1-d w_{16}\right)$, each with $25 \%$ probability. Assume that 


\begin{tabular}{|l||c|c|c|}
\hline & $w=300$ & $w=400$ & $w=500$ \\
\hline \hline $\mathrm{c}=1.5$ & $(0.140,0.260)$ & $(0.110,0.240)$ & $(0.090,0.230)$ \\
\hline $\mathrm{c}=2$ & $(0.140,0.220)$ & $(0.110,0.200)$ & $(0.090,0.190)$ \\
\hline $\mathrm{c}=2.5$ & $(0.135,0.194)$ & $(0.110,0.180)$ & $(0.095,0.165)$ \\
\hline
\end{tabular}

Table 2: Values of $\left(d w_{8}, d w_{16}\right)$ that yield the indifferences under constant discounting.

the individual satisfies constant discounting with an 8-weekly discount factor $\delta(8)=0.8 .{ }^{6}$

Table 2 gives values of $d w_{8}$ and $d w_{16}$ that yield the indifferences for each of the values of $c$ and $w$. More precisely, the values in Table 2 yield (0 weeks : 100) $\succ$ (8 weeks : 127),

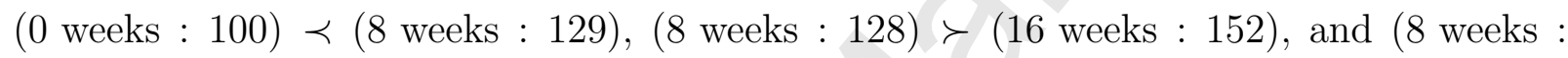
$128) \prec(16$ weeks : 154). In this example a higher endowment $w$ requires more change in risk and a higher coefficient of relative risk aversion requires less change in risk, if we measure change in risk as the difference between $d w_{16}$ and $d w_{8}$. This is consistent with the fact that the derivative of the coefficient of absolute risk aversion w.r.t. consumption $x$ is increasing in $x$ and decreasing in $c$. It is not clear, though, whether this is a general result which holds for all possible parameter values. Note that Theorem 3.4 describes the change in risk in terms of expected utilities. In this paper we have not explicitly defined a measure for the change in risk. We leave it to future research to define such a measure and to see whether the results of this example can be generalized.

\section{I-REVERSALS}

The previous results have shown that even though a d-reversal suggests decreasing impatience, it is consistent with a discount function that exhibits constant or even increasing impatience. More specifically, we have seen that if the increase in endowment risk in the

\footnotetext{
${ }^{6}$ This magnitude of the discount factor and the corresponding large discount rate is commonly found in experiments.
} 
far future is large compared to the increase in risk in the near future, then d-reversals can be observed for all types of discount functions. We will now consider an i-reversal, which suggests increasing impatience. Similar to the case of d-reversals analysed above, we will show that an i-reversal is consistent with a discount function that satisfies constant or even decreasing impatience.

\section{Definition 3.7 -reversal}

Induced preferences $\succcurlyeq^{*}$ exhibit an $i$-reversal at the outcomes $y>x>0$ and dates $\bar{t}>t \geq 0$ and $\tau>0$ if

$$
(t: x) \sim^{*}(t+\tau: y) \&(\bar{t}: x) \succ^{*}(\bar{t}+\tau: y) .^{7}
$$

An i-reversal suggests increasing impatience: the DM is indifferent between receiving $x$ at date $t$ and receiving $y, \tau$ periods later, but he is no longer willing to wait for $y$ if the delay is from the later date $\bar{t}$ to $\bar{t}+\tau$. Thus, the DM appears to be more impatient in the far future than in the near future. Indeed, if there were no risk, an i-reversal would imply increasing impatience.

A similar reasoning as for the d-reversal tells us that when the increase in endowment risk is larger in in the near than in the far future, an i-reversal will be observed, even under constant discounting. The following theorems formalize this intuition.

Theorem 3.8 Let the DM satisfy an i-reversal, i.e.

$$
(t: x) \sim^{*}(t+\tau: y) \&(\bar{t}: x) \succ^{*}(\bar{t}+\tau: y)
$$

where $y>x>0, \bar{t}>t \geq 0, \tau>0$. Then there exist endowments with increasing endowment risk, such that the reversal can be supported by a discount function satisfying constant impatience.

\footnotetext{
${ }^{7}$ If an i-reversal exists, then by continuity and monotonicity we can also find outcomes $x^{\prime}$ and $y^{\prime}$ close to $x$ and $y$ such that $\left(t: x^{\prime}\right) \prec^{*}\left(t+\tau: y^{\prime}\right) \&\left(\bar{t}: x^{\prime}\right) \succ^{*}\left(\bar{t}+\tau: y^{\prime}\right)$.
} 
Remark 3.9 The i-reversal in Theorem 3.8 can even be supported by a discount function satisfying decreasing impatience. In particular, it can be supported by a generalized hyperbolic discount function $\delta(t)=(1+\alpha t)^{-\beta / \alpha}$ for some $\alpha, \beta>0$.

The next theorem provides conditions for i-reversals to occur under constant impatience and given increasing endowment risk.

Theorem 3.10 Let $y>x>0, \bar{t}>t \geq 0$, and $\tau>0$. Let endowment risk be increasing and let the DM's discount function satisfy constant impatience. Then, for every $M$ there is an $N$ such that if

$$
\begin{aligned}
\left|\left[E U\left(\omega_{\bar{t}}+x\right)-E U\left(\omega_{\bar{t}}\right)\right]-\left[E U\left(\omega_{t}+x\right)-E U\left(\omega_{t}\right)\right]\right| & >M \text { and } \\
\left|\left[E U\left(\omega_{\bar{t}+\tau}+y\right)-E U\left(\omega_{\bar{t}+\tau}\right)\right]-\left[E U\left(\omega_{t+\tau}+y\right)-E U\left(\omega_{t+\tau}\right)\right]\right| & <N
\end{aligned}
$$

and if

$$
(t: x) \sim^{*}(t+\tau: y)
$$

then

$$
(\bar{t}: x) \succ^{*}(\bar{t}+\tau: y) .
$$

The crucial assumption in Theorem 3.10 is that the increase in endowment risk in the near future is relatively large (Eq. 4) compared to the increase in risk in the far future (Eq. 5).

Remark 3.11 If the DM has a generalized hyperbolic discount function $\delta(t)=(1+\alpha t)^{-\beta / \alpha}$ with $\alpha, \beta>0$, then, under the conditions of Theorem 3.10, $(t: x) \sim^{*}(t+\tau: y)$ implies that $(\bar{t}: x) \succ^{*}(\bar{t}+\tau: y)$ if $\alpha$ is sufficiently small.

A special case of increasing endowment risk that increases more in the near than in the far future, is the case with i.i.d. endowment risk. The following theorem shows that when endowment risk is i.i.d. we can predict an i-reversal whenever date 0 is involved. 
Theorem 3.12 Consider a DM with i.i.d. endowment-risk and let $\omega_{t}=\bar{\omega}$ for all $t \geq 1$ for some $\bar{\omega} \in \mathcal{R}$. Assume that $U\left(\omega_{0}\right)>E U(\bar{\omega})$ and $(0: x) \sim^{*}(\tau: y)$ where $y>x>0$ and $\tau>0$. If the DM's discount function satisfies constant impatience, then

$$
(t: x) \succ^{*}(t+\tau: y) \quad \text { for all } t>0
$$

A slightly weaker result holds if the discount function is of the generalized hyperbolic form, i.e. $\delta(t)=(1+\alpha t)^{-\beta / \alpha}$, with $\alpha, \beta>0$. In this case there will be an i-reversal for a given delay $t$ whenever $\alpha$ is sufficiently small. Moreover, if the DM has a generalized hyperbolic discount function and if there is an i-reversal for some delay $\bar{t}$, then any delay $t<\bar{t}$ also results in a strict preference for the earlier outcome. Thus, if we observe one ireversal, then we will observe many more i-reversals. We state these results in the following remark:

Remark 3.13 Under the conditions of Theorem 3.12 the following holds:

(i) For every $t>0$ there is an $A$ such that if the DM has a generalized hyperbolic discount function $\delta(t)=(1+\alpha t)^{-\beta / \alpha}$, with $\alpha, \beta>0$, i.e. the discount function satisfies decreasing impatience, and if $\alpha<A$ then $(t: x) \succ^{*}(t+\tau: y)$.

(ii) If the DM's discount function is given by $\delta(t)=(1+\alpha t)^{-\beta / \alpha}$, where $\alpha, \beta>0$, and if $(\bar{t}: x) \succ^{*}(\bar{t}+\tau: y)$, then $(t: x) \succ^{*}(t+\tau: y)$ for all $t$ with $0<t \leq \bar{t}$.

\section{Choices under outcome risk}

While in the previous section we only considered riskless outcomes, in this section we address the case of risky outcomes. This section formalizes the ideas of Keren and Roelofsma (1995). We assume that the DM perceives any outcome $x$ that is received at some date $t>0$ to be risky, i.e. the DM perceives the outcome to be $x+\varepsilon_{x, t}$ for some $\varepsilon_{x, t} \in \mathcal{R}$ with $E\left(\varepsilon_{x, t}\right)=0$ and $\operatorname{Prob}\left(\varepsilon_{x, t}=0\right)<1$. Any outcome $x$ to be received at $t=0$ is perceived to be riskless, i.e. we assume that $\varepsilon_{x, 0}=0$ for all $x \in \mathbb{R}$. Outcome risk for $x$ is i.i.d. if $\varepsilon_{x, t}$ is 
independently and identically distributed for all $t>0$. Outcome risk for $x$ is increasing if $\varepsilon_{x, \bar{t}}$ is a mean-preserving spread of $\varepsilon_{x, t}$ for all $0 \leq t<\bar{t} \leq T$.

In order to focus on the impact of outcome risk on behavior, throughout this section we will assume that endowments are stationary and riskless, i.e. $\omega=(w, \ldots, w)$ for some $w \in \mathbb{R}$. Thus, a DM who receives $(t: x)$ now consumes the consumption stream $\xi^{(t: x)}=$ $\left(\xi_{0}^{(t: x)}, \xi_{1}^{(t: x)}, \ldots, \xi_{T}^{(t: x)}\right) \in \mathcal{R}^{T+1}$ with $\xi_{t}^{(t: x)}=w+x+\varepsilon_{x, t}$ and $\xi_{t^{\prime}}^{(t: x)}=w$ for all $t^{\prime} \neq t$.

Throughout this section we assume that the expected utility of receiving a risky outcome on top of the endowment is finite.

Assumption III $\left|E U\left(w+x+\varepsilon_{x, t}\right)\right|<\infty$ for all $x \in \mathbb{R}$ and all $t=0, \ldots, T$.

\section{D-REVERSALS}

In Section 3 we showed that i-reversals at $t=0$ are supported by a discount function that satisfies constant or even decreasing impatience if endowment risk is i.i.d. Similarly, we now show that d-reversals at $t=0$ are supported by a discount function that satisfies constant or even increasing impatience if outcome risk is i.i.d. The intuition behind the result is as follows. Receiving a reward in the future instead of receiving it immediately has two drawbacks. First, under impatience a DM always prefers to receive a reward earlier. Second, in the future the reward will be subject to risk and a risk averse DM dislikes risk. Thus, for the DM to be indifferent between receiving reward $x$ today and receiving reward $y$ at the future date $\tau$, reward $y$ must be sufficiently superior to reward $x$ so that it offsets the two aforementioned drawbacks. Now assume that outcome risk is i.i.d. Delaying the receipt of both outcomes by $\bar{t}$ periods does not increase the risk of outcome $y$, but does increase the risk of outcome $x$. Thus, this delay makes outcome $x$ relatively less attractive, which results in a strict preference for the later outcome $y$.

Theorem 4.1 Consider a DM with riskless endowment and i.i.d. outcome-risk for all 
$x \in \mathbb{R}$. Let $\succcurlyeq^{*}$ exhibit a d-reversal at date 0 , i.e.

$$
(0: x) \sim^{*}(\tau: y) \&(\bar{t}: x) \prec^{*}(\bar{t}+\tau: y)
$$

where $y>x>0$ and $\bar{t}, \tau>0$. Then this reversal can be supported by a discount function satisfying constant impatience.

Remark 4.2 The d-reversal in Theorem 4.1 can even be supported by a discount function satisfying increasing impatience. In particular, in can be supported by the CRDI discount function $\delta(t)=\exp \left(-b t^{1+g}\right)$ for some $b, g>0$.

The following theorem makes behavioral predictions. If a DM is indifferent between receiving outcome $x$ today or outcome $y$ at the future date $\tau$, then constant impatience implies that delaying the receipt of both outcomes by $t$ periods results in a strict preference for the later outcome $y$.

Theorem 4.3 Consider a DM with riskless endowments and i.i.d. outcome-risk for all $x \in \mathbb{R}$. Let $(0: x) \sim^{*}(\tau: y)$ where $y>x>0$ and $\tau>0$. If the DM's discount function satisfies constant impatience, then $(t: x) \prec^{*}(t+\tau: y)$ for all $t>0$.

If the DM has a CRDI discount function $\delta(t)=\exp \left(-b t^{1+g}\right)$ with $b, g>0$ (i.e. increasing impatience), then there will be a d-reversal for a given delay $t$ whenever $g$ is sufficiently small. Finally, if $\delta(t)=\exp \left(-b t^{1+g}\right)$ and if there is a d-reversal for some delay $\bar{t}$, then any delay $t<\bar{t}$ also results in a strict preference for the later outcome. Thus, if we observe one d-reversal then we will observe many more d-reversals:

Remark 4.4 Under the conditions of Theorem 4.3 the following holds:

(i) For every $t>0$ there is a $G$ such that if the DM has a discount function $\delta(t)=$ $\exp \left(-b t^{1+g}\right)$ with $b, g>0$ and $g<G$ then $(t: x) \prec^{*}(t+\tau: y)$

(ii) If the DM's discount function is given by $\delta(t)=\exp \left(-b t^{1+g}\right)$ for some $b, g>0$, and if $(\bar{t}: x) \prec^{*}(\bar{t}+\tau: y)$, then $(t: x) \prec^{*}(t+\tau: y)$ for all $0<t \leq \bar{t}$. 
As long as outcome-risk increases relatively strongly in the near future compared to the far future, a d-reversal does not rule out constant impatience, even when outcome risk is not i.i.d. as is shown next.

Theorem 4.5 Let the DM satisfy a d-reversal, i.e.

$$
(t: x) \sim^{*}(t+\tau: y) \&(\bar{t}: x) \prec^{*}(\bar{t}+\tau: y)
$$

where $y>x>0, \bar{t}>t \geq 0$, and $\tau>0$. If outcome risk for $x$ is increasing, then there exists increasing risk for $y, \varepsilon_{y, t^{\prime}}, t^{\prime}=1, \ldots, T$, such that the d-reversal can be supported by a discount function satisfying constant impatience.

Remark 4.6 The d-reversal in Theorem 4.5 can even be supported by a discount function satisfying increasing impatience. In particular, it can be supported by the CRDI discount function $\delta(t)=\exp \left(-b t^{1+g}\right)$ for some $b, g>0$.

In Theorem 4.5 and Remark 4.6 we showed that there exist outcome risks $\varepsilon_{y, t^{\prime}}, t^{\prime}=$ $1, \ldots, T$, such that the d-reversal can be supported by a discount function satisfying constant or increasing impatience. In the proof we constructed an increasing outcome risk for $y$. Alternatively, we could have let outcome $y$ be riskless.

The next theorem shows that if outcome risk increases strongly in the near future and relatively weakly in the far future, then d-reversals occur whenever the discount function satisfies constant impatience.

Theorem 4.7 Let $y>x>0, \bar{t}>t \geq 0$, and $\tau>0$. Let outcome risk for $x$ and $y$ be increasing and let the DM's discount function satisfy constant impatience. Then, for every $M$ there is an $N$ such that if

$$
\begin{aligned}
\left|E U\left(w+x+\varepsilon_{x, t}\right)-E U\left(w+x+\varepsilon_{x, \bar{t}}\right)\right| & >M \text { and } \\
\left|E U\left(w+y+\varepsilon_{y, t+\tau}\right)-E U\left(w+y+\varepsilon_{y, \bar{t}+\tau}\right)\right| & <N .
\end{aligned}
$$

and if

$$
(t: x) \sim^{*}(t+\tau: y)
$$


then

$$
(\bar{t}: x) \prec^{*}(\bar{t}+\tau: y)
$$

Remark 4.8 If the DM has a CRDI discount function $\delta(t)=\exp \left(-b t^{1+g}\right)$ with $b, g>0$, then, under the conditions of Theorem $4.7(t: x) \sim^{*}(t+\tau: y)$ implies that $(\bar{t}: x) \prec^{*}$ $(\bar{t}+\tau: y)$ if $g$ is sufficiently small.

\section{I-REVERSALS}

We now consider i-reversals and show that as long as outcome risk increases relatively strongly in the far compared to the near future, an i-reversal does not rule out constant or decreasing impatience.

Theorem 4.9 Let the DM satisfy an i-reversal, i.e.

$$
(t: x) \sim^{*}(t+\tau: y) \&(\bar{t}: x) \succ^{*}(\bar{t}+\tau: y)
$$

where $y>x>0, \bar{t}>t \geq 0$, and $\tau>0$. If outcome risk for $y$ is increasing, then there exists increasing risk for $x, \varepsilon_{x, t^{\prime}}, t^{\prime}=1, \ldots, T$, such that the $i$-reversal can be supported by a discount function satisfying constant impatience.

Remark 4.10 The i-reversal in Theorem 4.9 can even be be supported by a discount function satisfying decreasing impatience. In particular, it can be supported by a generalized hyperbolic discount function $\delta(t)=(1+\alpha t)^{-\beta / \alpha}$ with $\alpha, \beta>0$.

Finally, Theorem 4.11 predicts that if outcome risk increases relatively strongly in the far future compared to the near future, then i-reversals occur whenever the discount function satisfies constant impatience.

Theorem 4.11 Let $y>x>0, \bar{t}>t \geq 0$, and $\tau>0$. Let outcome risk for $x$ and $y$ be increasing and let the DM's discount function satisfy constant impatience. Then, for every 
$M$ there is an $N$ such that if

$$
\begin{aligned}
\left|E U\left(w+y+\varepsilon_{y, t+\tau}\right)-E U\left(w+y+\varepsilon_{y, \bar{t}+\tau}\right)\right| & >M \text { and } \\
\left|E U\left(w+x+\varepsilon_{x, t}\right)-E U\left(w+x+\varepsilon_{x, \bar{t}}\right)\right| & <N
\end{aligned}
$$

and if

$$
(t: x) \sim^{*}(t+\tau: y)
$$

then

$$
(\bar{t}: x) \succ^{*}(\bar{t}+\tau: y) .
$$

Remark 4.12 If the DM has a generalized hyperbolic discount function $\delta(t)=(1+\alpha t)^{-\beta / \alpha}$ with $\alpha, \beta>0$, then, under the conditions of Theorem 4.11, $(t: x) \sim^{*}(t+\tau: y)$ implies that $(\bar{t}: x) \succ^{*}(\bar{t}+\tau: y)$ if $\alpha$ is sufficiently small.

\section{Discussion}

We have shown that non-stationary behavior can be observed whenever decision-makers perceive outcomes or endowments as risky. While we considered endowment risk and outcome-risk in isolation, it is obvious that similar results hold if both risks are perceived simultaneously. In this case both risks interact and the dominant change in risk over time determines the observed behavior. Thus, the result that decreasing and increasing impatience can be observed simultaneously, even under constant discounting, still holds with this richer structure in risk.

Our results indicate that one should be careful when drawing conclusions from experiments in intertemporal choice, because part of the results can be influenced by the subjects' perceptions of risk. It will be useful for researchers doing experiments on intertemporal choice to try to either elicit or control for the risk perception of subjects. Future research will deal with the extent to which this is possible. 


\section{Appendix}

\section{Proof of Theorem 3.2, Theorem 3.4, Remark 3.3 and Remark 3.5}

Consider endowments with increasing endowment-risk that satisfy Assumption II. We start by making an observation which will be helpful in the proof of the result.

Since $U^{\prime \prime \prime}>0$ by strictly decreasing absolute risk aversion and since $\omega_{\bar{t}}$ is a meanpreserving spread of $\omega_{t}$ for $\bar{t}>t$ it follows that

$$
E\left[\frac{d}{d z} U\left(\omega_{\bar{t}}+z\right)\right]>E\left[\frac{d}{d z} U\left(\omega_{t}+z\right)\right] .
$$

Thus,

$$
\frac{d}{d z} E U\left(\omega_{\bar{t}}+z\right)>\frac{d}{d z} E U\left(\omega_{t}+z\right)
$$

for all $z \in \mathbb{R}$.

Thus,

$$
E U\left(\omega_{t}+x\right)-E U\left(\omega_{t}\right)<E U\left(\omega_{\bar{t}}+x\right)-E U\left(\omega_{\bar{t}}\right)
$$

for all $x>0$.

We can now start with the proof of our results. By $(t: x) \sim^{*}(t+\tau: y)$ we know that for the reversal to be supported by a discount function $\delta$ we need

$$
\delta(t)\left[E U\left(\omega_{t}+x\right)-E U\left(\omega_{t}\right)\right]=\delta(t+\tau)\left[E U\left(\omega_{t+\tau}+y\right)-E U\left(\omega_{t+\tau}\right)\right] .
$$

By the argument above it follows that

$$
E U\left(\omega_{\bar{t}+\tau}+y\right)-E U\left(\omega_{\bar{t}+\tau}\right)>E U\left(\omega_{t+\tau}+y\right)-E U\left(\omega_{t+\tau}\right) .
$$

Hence, whenever $\delta$ satisfies constant or decreasing impatience we have

$$
E U\left(\omega_{\bar{t}+\tau}+y\right)-E U\left(\omega_{\bar{t}+\tau}\right)>\frac{\delta(t+\tau) \delta(\bar{t})}{\delta(t) \delta(\bar{t}+\tau)}\left[E U\left(\omega_{t+\tau}+y\right)-E U\left(\omega_{t+\tau}\right)\right] .
$$

Together with (7) this implies

$$
E U\left(\omega_{\bar{t}+\tau}+y\right)-E U\left(\omega_{\bar{t}+\tau}\right)>\frac{\delta(\bar{t})}{\delta(\bar{t}+\tau)}\left[E U\left(\omega_{t}+x\right)-E U\left(\omega_{t}\right)\right]
$$


For increasing impatience consider the discount function $\delta(t)=\exp \left(-b t^{1+g}\right)$ for $b, g>0$. Define

$$
b=b(g):=\frac{\ln (A)}{(t+\tau)^{1+g}-t^{1+g}},
$$

where

$$
A:=\frac{E U\left(\omega_{t+\tau}+y\right)-E U\left(\omega_{t+\tau}\right)}{E U\left(\omega_{t}+x\right)-E U\left(\omega_{t}\right)} .
$$

Then (7) is satisfied for all $g>0$. It is immediate to see that $\delta\left(t^{\prime}\right) \rightarrow A^{-t^{\prime} / \tau}$ for all $t^{\prime}$ if $g \rightarrow 0$. Hence,

$$
\lim _{g \rightarrow 0} \frac{\delta(t+\tau) \delta(\bar{t})}{\delta(t) \delta(\bar{t}+\tau)}=1
$$

Thus, for $g$ sufficiently small both (7) and (8) are satisfied, which again implies (9).

It remains to show that there exist endowments with increasing endowment risk such that $E U\left(\omega_{t}+x\right)-E U\left(\omega_{t}\right)$ is sufficiently close to $E U\left(\omega_{\bar{t}}+x\right)-E U\left(\omega_{\bar{t}}\right)$ so that

$$
E U\left(\omega_{\bar{t}+\tau}+y\right)-E U\left(\omega_{\bar{t}+\tau}\right)>\frac{\delta(\bar{t})}{\delta(\bar{t}+\tau)}\left[E U\left(\omega_{\bar{t}}+x\right)-E U\left(\omega_{\bar{t}}\right)\right] .
$$

To see this let $\gamma, \lambda>0$, and let $\varepsilon_{t} \in \mathcal{R}$ be uniformly and independently distributed on $[-\gamma, \gamma]$ for all $t=1, \ldots, \bar{t}$, and let $\varepsilon_{t} \in \mathcal{R}$ be uniformly distributed on $[-\lambda, \lambda]$ for all $t=\bar{t}+1, \ldots, T$. Let $\omega_{t}=\omega_{0}+\sum_{k=1}^{t} \varepsilon_{k}$ for $t=1, \ldots, T$. Then $\omega_{t^{\prime}}$ is a mean-preserving spread of $\omega_{t}$ for all $t^{\prime}>t$. By continuity of $U$ it follows that $E U\left(\omega_{\bar{t}}+x\right)-E U\left(\omega_{\bar{t}}\right)$ converges to $E U\left(\omega_{t}+x\right)-E U\left(\omega_{t}\right)$ if $\gamma$ goes to 0, while the inequality in (8) still holds in the limit. It follows that $(\bar{t}: x) \prec^{*}(\bar{t}+\tau: y)$. This proves Theorem 3.2 and Remark 3.3.

To prove Theorem 3.4 and Remark 3.5 note that from $(t: x) \sim^{*}(t+\tau: y)$ and $\left|\left[E U\left(\omega_{\bar{t}+\tau}+y\right)-E U\left(\omega_{\bar{t}+\tau}\right)\right]-\left[E U\left(\omega_{t+\tau}+y\right)-E U\left(\omega_{t+\tau}\right)\right]\right|>M$ it follows that $(7)$ and $(8)$ hold whenever $\delta$ satisfies decreasing or constant impatience or whenever $\delta(t)=\exp \left(-b t^{1+g}\right)$ for $b>0$ and $g>0$ sufficiently small. Hence, by the same argument as in the first part of the proof, if for given $M,\left|\left[E U\left(\omega_{\bar{t}}+x\right)-E U\left(\omega_{\bar{t}}\right)\right]-\left[E U\left(\omega_{t}+x\right)-E U\left(\omega_{t}\right)\right]\right|$ is sufficiently small, then $(\bar{t}: x) \prec^{*}(\bar{t}+\tau: y)$. This proves Theorem 3.4 and Remark 3.5. 


\section{Proof of Theorem 3.8, Theorem 3.10, Remark 3.9 and Remark 3.11}

Consider endowments with increasing endowment-risk that satisfy Assumption II. By the same argument as in the proof of Theorem 3.2 it follows that

$$
E U\left(\omega_{t}+x\right)-E U\left(\omega_{t}\right)<E U\left(\omega_{\bar{t}}+x\right)-E U\left(\omega_{\bar{t}}\right)
$$

for all $x>0$. From $(t: x) \sim^{*}(t+\tau: y)$ we know that for the reversal to be supported by a discount function $\delta$ we need

$$
\delta(t)\left[E U\left(\omega_{t}+x\right)-E U\left(\omega_{t}\right)\right]=\delta(t+\tau)\left[E U\left(\omega_{t+\tau}+y\right)-E U\left(\omega_{t+\tau}\right)\right] .
$$

Consider the inequality

$$
\frac{\delta(t+\tau) \delta(\bar{t})}{\delta(t) \delta(\bar{t}+\tau)}\left[E U\left(\omega_{\bar{t}}+x\right)-E U\left(\omega_{\bar{t}}\right)\right]>E U\left(\omega_{t}+x\right)-E U\left(\omega_{t}\right) .
$$

Note first that for increasing and constant impatience the foregoing inequality always holds by (10). For decreasing impatience consider the generalized hyperbolic discount function $\delta(t)=(1+\alpha t)^{-\beta / \alpha}$ with $\alpha, \beta>0$. If we let

$$
\beta=\beta(\alpha):=-\alpha A(\alpha)
$$

where

$$
A(\alpha):=\ln \left(\frac{E U\left(\omega_{t}+x\right)-E U\left(\omega_{t}\right)}{E U\left(\omega_{t+\tau}+y\right)-E U\left(\omega_{t+\tau}\right)}\right) / \ln \left(\frac{1+\alpha(t+\tau)}{1+\alpha t}\right) .
$$

then (11) is satisfied for any $\alpha>0$. It is straightforward to show that

$$
\lim _{\alpha \rightarrow 0} \frac{\delta(t+\tau) \delta(\bar{t})}{\delta(t) \delta(\bar{t}+\tau)}=\lim _{\alpha \rightarrow 0}\left[\frac{(1+\alpha(t+\tau))(1+\alpha \bar{t})}{(1+\alpha t)(1+\alpha(\bar{t}+\tau))}\right]^{A(\alpha)}=1 .
$$

Hence, for $\alpha$ sufficiently small both (11) and (12) are satisfied. Now we see that if

$$
E U\left(\omega_{t+\tau}+y\right)-E U\left(\omega_{t+\tau}\right)
$$

is sufficiently close to

$$
E U\left(\omega_{\bar{t}+\tau}+y\right)-E U\left(\omega_{\bar{t}+\tau}\right)
$$


then from (11) and (12) it follows that

$$
\delta(\bar{t})\left[E U\left(\omega_{\bar{t}}+x\right)-E U\left(\omega_{\bar{t}}\right)\right]>\delta(\bar{t}+\tau)\left[E U\left(\omega_{\bar{t}+\tau}+y\right)-E U\left(\omega_{\bar{t}+\tau}\right)\right] .
$$

Hence, the i-reversal

$$
(t: x) \sim^{*}(t+\tau, y) \&(\bar{t}: x) \succ^{*}(\bar{t}+\tau: y)
$$

can be supported by a discount function satisfying increasing, constant or decreasing impatience.

It remains to be shown that there exist endowments with increasing endowment risk such that $E U\left(\omega_{t+\tau}+y\right)-E U\left(\omega_{t+\tau}\right)$ is close to $E U\left(\omega_{\bar{t}+\tau}+y\right)-E U\left(\omega_{\bar{t}+\tau}\right)$. To see this let $\gamma>0$ and let $\varepsilon_{i} \in \mathcal{R}$ be uniformly and independently distributed on $[-\gamma, \gamma]$ for all $i=1, \ldots, T-t-\tau$. Let $\omega_{t+\tau+i}=\omega_{t+\tau}+\sum_{k=1}^{i} \varepsilon_{k}$ for $i=1, \ldots, T-t-\tau$. Then $\omega_{t+\tau+j}$ is a mean-preserving spread of $\omega_{t+\tau+i}$ for all $j>i$. By continuity of $U$ it follows that $E U\left(\omega_{\bar{t}+\tau}+y\right)-E U\left(\omega_{\bar{t}+\tau}\right)$ converges to $E U\left(\omega_{t+\tau}+y\right)-E U\left(\omega_{t+\tau}\right)$ if $\gamma$ goes to 0 while the inequality in (12) still holds in the limit. This proves Theorem 3.8 and Remark 3.9.

To prove Theorem 3.10 and Remark 3.11 note that from $(t: x) \sim^{*}(t+\tau: y)$ and $\left|\left[E U\left(\omega_{\bar{t}}+x\right)-E U\left(\omega_{\bar{t}}\right)\right]-\left[E U\left(\omega_{t}+x\right)-E U\left(\omega_{t}\right)\right]\right|>M$ it follows that (11) and (12) hold whenever $\delta$ satisfies increasing or constant impatience or whenever $\delta$ is of the generalized hyperbolic form, i.e. $\delta(t)=(1+\alpha t)^{-\beta / \alpha}$ with $\beta>0$ and $\alpha>0$ sufficiently small (cf. the argument above). Hence, by the same argument as in the first part of the proof, if for given $M,\left|\left[E U\left(\omega_{\bar{t}+\tau}+y\right)-E U\left(\omega_{\bar{t}+\tau}\right)\right]-\left[E U\left(\omega_{t+\tau}+y\right)-E U\left(\omega_{t+\tau}\right)\right]\right|$ is sufficiently small, then $(\bar{t}: x) \succ^{*}(\bar{t}+\tau: y)$. This proves Theorem 3.10 and Remark 3.11.

\section{Proof of Theorem 3.12 and Remark 3.13}

The i-reversal can be supported by a discount function $\delta$ if

$$
U\left(\omega_{0}+x\right)-U\left(\omega_{0}\right)=\delta(\tau)[E U(\bar{\omega}+y)-E U(\bar{\omega})]
$$

and

$$
\delta(\bar{t})[E U(\bar{\omega}+x)-E U(\bar{\omega})]>\delta(\bar{t}+\tau)[E U(\bar{\omega}+y)-E U(\bar{\omega})] .
$$


From $U\left(\omega_{0}\right)>E U(\bar{\omega})$ and the strict concavity of $U$ it follows that

$$
U\left(\omega_{0}\right)-U(E(\bar{\omega})-\pi(0, \bar{\omega}))>U\left(\omega_{0}+x\right)-U(x+E(\bar{\omega})-\pi(0, \bar{\omega})) .
$$

Strictly decreasing absolute risk aversion implies that $\pi(x, \bar{\omega})<\pi(0, \bar{\omega})$. Thus,

$$
U\left(\omega_{0}\right)-U(E(\bar{\omega})-\pi(0, \bar{\omega}))>U\left(\omega_{0}+x\right)-U(x+E(\bar{\omega})-\pi(x, \bar{\omega})) .
$$

It follows that

$$
E U(\bar{\omega}+x)-E U(\bar{\omega})>U\left(\omega_{0}+x\right)-U\left(\omega_{0}\right)
$$

Thus, there exists $\delta(\tau)<1$ such that (13) holds. Then (14) is satisfied if and only if

$$
\frac{\delta(\tau) \delta(\bar{t})}{\delta(\bar{t}+\tau)}[E U(\bar{\omega}+x)-E U(\bar{\omega})]>U\left(\omega_{0}+x\right)-U\left(\omega_{0}\right)
$$

which holds for any discount function $\delta$ that satisfies increasing or constant impatience. Thus, we have shown that the i-reversal can be supported by any discount function satisfying increasing or constant impatience and (13).

For decreasing impatience consider the generalized hyperbolic discount function $\delta(t)=$ $(1+\alpha t)^{-\beta / \alpha}$ with $\alpha, \beta>0$. By a similar argument as in the proof of Remark 3.9 there exist $\alpha>0$ and $\beta>0$ such that both (13) and (15) are satisfied which proves Theorem 3.12 and $(i)$ in Remark 3.13 .

We will now prove $(i i)$ in Remark 3.13. Assume that $(0: x) \sim^{*}(\tau: y)$ and $(\bar{t}: x) \succ^{*}$ $(\bar{t}+\tau: y)$. From the argument above we know that it must be the case that

$$
1>\frac{\delta(\tau) \delta(\bar{t})}{\delta(\bar{t}+\tau)}>\frac{U\left(\omega_{0}+x\right)-U\left(\omega_{0}\right)}{E U(\bar{\omega}+x)-E U(\bar{\omega})} .
$$

Consider the function

$$
f(t)=\frac{\delta(\tau) \delta(t)}{\delta(t+\tau)}=\frac{(1+\alpha \tau)^{-\beta / \alpha}(1+\alpha t)^{-\beta / \alpha}}{(1+\alpha(t+\tau))^{-\beta / \alpha}} .
$$

It can easily be checked that $f(t)$ is strictly decreasing in $t>0$. Thus,

$$
1>\frac{\delta(\tau) \delta(t)}{\delta(t+\tau)}>\frac{U\left(\omega_{0}+x\right)-U\left(\omega_{0}\right)}{E U(\bar{\omega}+x)-E U(\bar{\omega})}
$$


for all $t \leq \bar{t}$. It follows that $(t: x) \succ^{*}(t+\tau: y)$ for all $t$ with $0<t \leq \bar{t}$ which proves Remark 3.13.

\section{Proof of Theorem 4.1, Theorem 4.3, Remark 4.2 and Remark 4.4}

Induced preferences exhibit the d-reversal $(0: x) \sim^{*}(\tau: y)$ and $(\bar{t}: x) \prec^{*}(\bar{t}+\tau: y)$ if and only if the discount function satisfies

$$
\begin{aligned}
U(w+x)-U(w) & =\delta(\tau)\left[E U\left(w+y+\varepsilon_{y}\right)-U(w)\right], \\
\text { and } \delta(\bar{t}+\tau)\left[E U\left(w+y+\varepsilon_{y}\right)-U(w)\right] & >\delta(\bar{t})\left[E U\left(w+x+\varepsilon_{x}\right)-U(w)\right],
\end{aligned}
$$

which is equivalent to

$$
\begin{aligned}
U(w+x)-U(w) & =\delta(\tau)\left[E U\left(w+y+\varepsilon_{y}\right)-U(w)\right] \\
\text { and } \quad U(w+x)-U(w) & >\frac{\delta(\tau) \delta(\bar{t})}{\delta(\bar{t}+\tau)}\left[E U\left(w+x+\varepsilon_{x}\right)-U(w)\right] .
\end{aligned}
$$

By strict concavity of $U$ we have $U(w+x)>E U\left(w+x+\varepsilon_{x}\right)$. Hence, the d-reversal is supported by any discount function that satisfies decreasing or constant impatience and for which $\delta(\tau)$ satisfies (17). It is also supported by any discount function that satisfies increasing impatience as long as the increase in impatience is sufficiently moderate, so that (18) holds. For a particular class of discount functions satisfying increasing impatience consider the discount function $\delta(t)=\exp \left(-b t^{1+g}\right)$ for $b, g>0$. By a similar argument as in the proof of Remark 3.3 one can show that there exist parameters $b$ and $g$ with $g$ sufficiently close to zero such that $\delta$ satisfies (17) and (18). This proves Theorem 4.1 and Remark 4.2 .

The proof of Theorem 4.3 and $(i)$ in Remark 4.4 follows from the above reasoning. We will now prove $(i i)$ in Remark 4.4. Assume that $(0: x) \sim^{*}(\tau: y)$ and $(\bar{t}: x) \prec^{*}(\bar{t}+\tau: y)$. Then

$$
U(w+x)-U(w)>\frac{\delta(\tau) \delta(\bar{t})}{\delta(\bar{t}+\tau)}\left[E U\left(w+x+\varepsilon_{x}\right)-U(w)\right]
$$


Consider the function

$$
f(t)=\frac{\delta(\tau) \delta(t)}{\delta(t+\tau)}=\exp \left[-b\left(\tau^{1+g}+t^{1+g}-(t+\tau)^{1+g}\right)\right]
$$

It can easily be checked that $f(t)$ is strictly increasing in $t$. Thus,

$$
U(w+x)-U(w)>\frac{\delta(\tau) \delta(t)}{\delta(t+\tau)}\left[E U\left(w+x+\varepsilon_{x}\right)-U(w)\right]
$$

for all $t \leq \bar{t}$. Hence, $(t: x) \prec^{*}(t+\tau: y)$ for all $t$ with $0<t \leq \bar{t}$ which proves $(i i)$ in Remark 4.4.

\section{Proof of Theorems 4.5, Theorem 4.7, Remark 4.6 and Remark 4.8}

From $(t: x) \sim^{*}(t+\tau: y)$ it follows that the discount function $\delta$ must satisfy

$$
\delta(t)\left[E U\left(w+x+\varepsilon_{x, t}\right)-U(w)\right]=\delta(t+\tau)\left[E U\left(w+y+\varepsilon_{y, t+\tau}\right)-U(w)\right] .
$$

If outcome risk for $x$ is increasing then

$$
E U\left(w+x+\varepsilon_{x, t}\right)-U(w)>E U\left(w+x+\varepsilon_{x, \bar{t}}\right)-U(w) .
$$

Hence, if $\delta$ satisfies decreasing or constant impatience we have

$$
E U\left(w+x+\varepsilon_{x, t}\right)-U(w)>\frac{\delta(t+\tau) \delta(\bar{t})}{\delta(t) \delta(\bar{t}+\tau)} E U\left(w+x+\varepsilon_{x, \bar{t}}\right)-U(w) .
$$

By a similar reasoning as in the proof of Theorem 3.2, there exist $b, g>0$ with $g$ close to zero such that (19) and (20) also hold for $\delta(t)=\exp \left(-b t^{1+g}\right)$, i.e. for a discount function that satisfies increasing impatience. From (19) and (20) it follows that

$$
E U\left(w+y+\varepsilon_{y, t+\tau}\right)-U(w)>\frac{\delta(\bar{t})}{\delta(\bar{t}+\tau)} E U\left(w+x+\varepsilon_{x, \bar{t}}\right)-U(w) .
$$

Hence, if $E U\left(w+y+\varepsilon_{y, \bar{t}+\tau}\right)$ is close to $E U\left(w+y+\varepsilon_{y, t+\tau}\right)$, then

$$
E U\left(w+y+\varepsilon_{y, \bar{t}+\tau}\right)-U(w)>\frac{\delta(\bar{t})}{\delta(\bar{t}+\tau)} E U\left(w+x+\varepsilon_{x, \bar{t}}\right)-U(w),
$$


which implies $(\bar{t}: x) \prec^{*}(\bar{t}+\tau: y)$. It remains to show that there exist $\varepsilon_{y, t^{\prime}}, t^{\prime}=1, \ldots, T$, such that $E U\left(w+y+\varepsilon_{y, \bar{t}+\tau}\right)$ is close to $E U\left(w+y+\varepsilon_{y, t+\tau}\right)$. Let $\gamma>0$ and let $\varepsilon_{t^{\prime}}$ be independently and uniformly distributed on $[-\gamma, \gamma]$ for all $t^{\prime}=1, \ldots, T$. Let $\varepsilon_{y, t^{\prime}}=$ $\varepsilon_{1}+\cdots+\varepsilon_{t^{\prime}}$ for all $t^{\prime}=1, \ldots, T$. By continuity of $U$ it follows that $E U\left(w+y+\varepsilon_{y, \bar{t}+\tau}\right)$ converges to $E U\left(w+y+\varepsilon_{y, t+\tau}\right)$ if $\gamma$ goes to 0 . This proves Theorem 4.5 and Remark 4.6.

To prove Theorem 4.7 and Remark 4.8 note that from $(t: x) \sim^{*}(t+\tau: y)$ and

$$
\left|E U\left(w+x+\varepsilon_{x, t}\right)-E U\left(w+x+\varepsilon_{x, \bar{t}}\right)\right|>M
$$

it follows that (19) and (20) hold whenever $\delta$ satisfies decreasing or constant impatience or whenever $\delta(t)=\exp \left(-b t^{1+g}\right)$ for $b>0$ and $g>0$ sufficiently small. Hence, by the same argument as in the first part of the proof, if for given $M, \mid E U\left(w+y+\varepsilon_{y, t+\tau}\right)-$ $E U\left(w+y+\varepsilon_{y, \bar{t}+\tau}\right) \mid$ is sufficiently small, then $(\bar{t}: x) \prec^{*}(\bar{t}+\tau: y)$ which proves Theorem 4.7 and 4.8 .

\section{Proof of Theorems 4.9, Theorem 4.11, Remark 4.10 and Remark 4.12}

From $(t: x) \sim^{*}(t+\tau: y)$ it follows that the discount function $\delta$ must satisfy

$$
\delta(t)\left[E U\left(w+x+\varepsilon_{x, t}\right)-U(w)\right]=\delta(t+\tau)\left[E U\left(w+y+\varepsilon_{y, t+\tau}\right)-U(w)\right]
$$

Since outcome risk for $y$ is increasing we know that

$$
E U\left(w+y+\varepsilon_{y, t+\tau}\right)-U(w)>E U\left(w+y+\varepsilon_{y, \bar{t}+\tau}\right)-U(w)
$$

Hence, if $\delta$ satisfies increasing or constant impatience we have

$$
\frac{\delta(t+\tau) \delta(\bar{t})}{\delta(t) \delta(\bar{t}+\tau)} E U\left(w+y+\varepsilon_{y, t+\tau}\right)-U(w)>E U\left(w+y+\varepsilon_{y, \bar{t}+\tau}\right)-U(w) .
$$

By a similar reasoning as in the proof of Remark 3.3, there exist $\alpha, \beta>0$ with $\alpha$ close to zero such that $(21)$ and $(22)$ also hold for $\delta(t)=(1+\alpha t)^{-\beta / \alpha}$, i.e. for a discount function that satisfies decreasing impatience. From (21) and (22) it follows that

$$
\frac{\delta(\bar{t})}{\delta(\bar{t}+\tau)} E U\left(w+x+\varepsilon_{x, t}\right)-U(w)>E U\left(w+y+\varepsilon_{y, \bar{t}+\tau}\right)-U(w) .
$$


Hence, if $E U\left(w+x+\varepsilon_{x, \bar{t}}\right)$ is close to $E U\left(w+x+\varepsilon_{x, t}\right)$, then

$$
\frac{\delta(\bar{t})}{\delta(\bar{t}+\tau)} E U\left(w+x+\varepsilon_{x, \bar{t}}\right)-U(w)>E U\left(w+y+\varepsilon_{y, \bar{t}+\tau}\right)-U(w) .
$$

which implies $(\bar{t}: x) \succ^{*}(\bar{t}+\tau: y)$. It remains to show that there exist $\varepsilon_{x, t^{\prime}}, t^{\prime}=1, \ldots, T$, such that $E U\left(w+x+\varepsilon_{x, \bar{t}}\right)$ is close to $E U\left(w+x+\varepsilon_{x, t}\right)$. This follows from a similar argument as in the proof of Theorem 4.5. This proves Theorem 4.9 and Remark 4.9. The proof of Theorem 4.11 and Remark 4.12 is similar to the proof of Theorem 4.7 and Remark 4.8.

\section{References}

Angeletos, G.M., Laibson, D., Repetto, A., Tobacman, J., Weinberg, S., 2001. The hyperbolic consumption model: calibration, simulation, and empirical evaluation. Journal of Economic Perspectives 15, 47-68.

Attema, A.E., Bleichrodt, H., Rohde, K.I.M., Wakker, P.P., 2010. Time-tradeoff sequences for analyzing discounting and time inconsistency. Management Science, forthcoming.

Barro, R.J., 1999. Ramsey meets Laibson in the neoclassical growth model. Quarterly Journal of Economics 114, 1125-1152.

Benzion, U., Rapoport, A., Yagil, J., 1989. Discount rates inferred from decisions: An experimental study. Management Science 35, 270-284.

Bleichrodt, H., Johannesson, M., 2001. Time preference for health: A test of stationarity versus decreasing timing aversion. Journal of Mathematical Psychology 45, 265-282.

Bleichrodt, H., Rohde, K.I.M., Wakker, P.P., 2009. Non-hyperbolic time inconsistency. Games and Economic Behavior 66, 27-38.

Bommier, A., 2006. Uncertain lifetime and intertemporal choice: Risk aversion as a rationale for time discounting. International Economic Review 47, 1223-1246.

Boyarchenko, S., Levendorskii, S., 2006. Discount factors ex post and ex ante, and discounted utility anomalies. mimeo.

Cairns, J., van der Pol, M., 2000. Valuing future private and social benefits: The discounted utility model versus hyperbolic discounting models. Journal of Economic Psychology 
$21,191-205$.

Chesson, H.W., Viscusi, W.K., 2003. Commonalities in time and ambiguity aversion for long-term risks. Theory and Decision 54, 57-71.

Dasgupta, P., Maskin, E., 2005. Uncertainty and hyperbolic discounting. American Economic Review 95, 1290-1299.

Ebert, J.E.J., Prelec, D., 2007. The fragility of time: time-insensitivity and valuation of the near and far future. Management Science 53, 1423-1438.

Eeckhoudt, L., Gollier, C., Schlesinger, H., 1996. Changes in background risk and risk taking behavior. Econometrica 64, 683-689.

Fernández-Villaverde, J., Mukherji, A., 2006. Can we really observe hyperbolic discounting? mimeo.

Frederick, S., 1999. Discounting, time preference, and identity. Ph.D. Thesis, Department of Social and Decision Sciences, Carnegie Mellon University.

Frederick, S., Loewenstein, G., O’Donoghue, T., 2002. Time discounting and time preference: a critical review. Journal of Economic Literature 40, 351-401.

Gigliotti, G., Sopher, B., 2003. Analysis of intertemporal choice: A new framework and experimental results. Theory and Decision 55, 209-233.

Gollier, C., Pratt, J.W., 1996. Risk vulnerability and the tempting effect of background risk. Econometrica 64, 1109-1123.

Green, L., Fristoe, N., Myerson, J., 1994. Temporal discounting and preference reversals in choice between delayed outcomes. Psychonomic Bulletin and Review 1, 383-389.

Halevy, Y., 2008. Strotz meets Allais: Diminishing impatience and the certainty effect. American Economic Review 98, 1145-1162.

Harris, C., Laibson, D., 2001. Dynamic choices of hyperbolic consumers. Econometrica 69, 935-957.

Herings, P.J.J., Rohde, K.I.M., 2006. Time-inconsistent preferences in a general equilibrium model. Economic Theory 29, 591-619.

Kahneman, D., Tversky, A., 1979. Prospect theory: An analysis of decision under risk. Econometrica 47, 263-291. 
Keren, G., Roelofsma, P., 1995. Immediacy and certainty in intertemporal choice. Organizational Behavior and Human Decision Processes 63, 287-297.

Kirby, K.N., Maraković, N.N., 1995. Modeling myopic decisions: Evidence for hyperbolic delay-discounting within subjects and amounts. Organizational Behavior and Human Decision Processes 64, 22-30.

Krusell, P., Smith, A.A., 2003. Consumption-savings decisions with quasi-geometric discounting. Econometrica 71, 365-375.

Laibson, D., 1997. Golden eggs and hyperbolic discounting. Quarterly Journal of Economics $112,443-477$.

Loewenstein, G., Prelec, D., 1992. Anomalies in intertemporal choice: Evidence and an interpretation. Quarterly Journal of Economics 107, 573-597.

Luttmer, E.G.J., Mariotti, T., 2003. Subjective discounting in an exchange economy. Journal of Political Economy 111, 1-30.

Luttmer, E.G.J., Mariotti, T., 2006. Efficiency and equilibrium when preferences are timeinconsistent. Journal of Economic Theory 132, 493-506.

Mazur, J.E., 1987. An adjusting procedure for studying delayed reinforcement. In: Mazur, J.E., Commons, M.L., Nevin, J.A., Rachlin, H. (Eds.). Quantitative Analyses of Behavior, Vol. 5: The Effect of Delay and of Intervening Events on Reinforcement Value. Hillsdale, NJ: Erlbaum, 55-73.

Mazur, J.E., 2001. Hyperbolic value addition and general models of animal choice. Psychological Review 108, 96-112.

Noor, J., 2009. Hyperbolic discounting and the standard model: Eliciting discount functions. Journal of Economic Theory 144, 2077-2083.

O’Donoghue, T., Rabin, M., 1999a. Doing it now or later. American Economic Review 89, 103-124.

O’Donoghue, T., Rabin, M., 1999b. Incentives for procrastinators. Quarterly Journal of Economics 114, 769-816.

Onay, S., Öncüler, A., 2007. Intertemporal choice under timing risk: An experimental approach. Journal of Risk and Uncertainty 34, 99-121. 
Phelps, E.S., Pollak, R.A., 1968. On second-best national saving and game-equilibrium growth. Review of Economic Studies 35, 185-199.

Pratt, J.W., 1964. Risk aversion in the small and in the large. Econometrica 32, 122-136.

Prelec, D., 2004. Decreasing impatience: A criterion for non-stationary time preference and 'hyperbolic' discounting. Scandinavian Journal of Economics 106, 511-532.

Read, D., Read, N.L., 2004. Time discounting over the lifespan. Organizational Behavior and Human Decision Processes 94, 22-32.

Read, D., Roelofsma, P.H.M.P., 2003. Subadditive versus hyperbolic discounting: A comparison of choice and matching. Organizational Behavior and Human Decision Processes $91,140-153$.

Read, D., Airoldi, M., Loewe, G., 2005. Intertemporal tradeoff priced in interest rates and amounts: A study of method variance. mimeo.

Read, D., Frederick, S., Orsel, B., Rahman, J., 2005. Four score and seven years from now: The 'date/delay effect' in temporal discounting. Management Science 51, 1326-1335.

Rodriguez, M.L., Logue, A.W., 1988. Adjusting delay to reinforcement: Comparing choice in pigeons and humans. Journal of Experimental Psychology: Animal Behavior Processes $14,105-117$.

Rohde, K.I.M., 2008. Arbitrage opportunities in frictionless markets with sophisticated investors. Economic Theory 34, 389-393.

Rubinstein, A., 2003. 'Economics and psychology'? The case of hyperbolic discounting. International Economic Review 44, 1207-1216.

Samuelson, P., 1937. A note on the measurement of utility. Review of Economic Studies 4, 155-161.

Sayman, S., Öncüler, A., 2009. An investigation of time-inconsistency. Management Science 55, 470-482.

Strotz, R.H., 1956. Myopia and inconsistency in dynamic utility maximization. Review of Economic Studies 23, 165-180.

Thaler, R., 1981. Some empirical evidence on dynamic inconsistency. Economics Letters 8, 201-207. 
Thaler, R.H., Benartzi, S., 2004. Save more tomorrow: Using behavioral economics to increase employee saving. Journal of Political Economy 112, 164-187. 